\title{
A Brief History of English Bird Names and the American Ornithologists' Union (now American Ornithological Society)
}

3

4 Kevin Winker

5

\section{Introduction}

University of Alaska Museum, 907 Yukon Drive, Fairbanks, Alaska 99775. kevin.winker@alaska.edu

\begin{abstract}
English bird names exist to increase the effectiveness of communication and to make ornithology more accessible to English speakers and readers. This was recognized from the first edition of the Check-list, when it was considered important to include a vernacular and technical name for each taxon (AOU 1886:15). Every edition of the Check-list and its Supplements have included English names for this purpose. Improving communication is an important job, and to be effective a name choice usually has to be made, especially among widespread birds with many vernacular names. The Check-list has been the standard for North America for over a century, and underpins the legal basis for the management and conservation of avian diversity across most of the continent. Choices for the English names given in the Check-list have been made under clear criteria and guidelines (Appendices I-III) that are responsive both to increased scientific knowledge and to changing societal mores (AOS NACC 2020). For more than a century, and for many different reasons, many people have been unhappy with choices made about particular English bird names and about the underlying processes. From the published history alone, it is clear that no process will achieve universal consensus, yet there remain many emergent merits to a standardized and widely adopted approach to English bird names.
\end{abstract}

Keywords: bird names, history, English, checklist

Early works in ornithology commonly included English names for the birds treated, going back to the first English text on birds (Willughby and Ray 1678). This tradition was carried on in North American ornithology throughout the $19^{\text {th }}$ century in major works by Wilson, Nuttall, Audubon, Coues, Baird, Cassin, Lawrence, and others. From 1886 onward, the American Ornithologists' Union (AOU; now American Ornithological Society, AOS) has produced the Check- 
33 list of North American Birds, the most widely accepted, authoritative list of avian diversity for North

34 America, now extending through seven editions and sixty-one Supplements. From the beginning,

35 the Check-list has included a single vernacular English name, capitalized and considered now as a

36 proper noun or proper name, for each taxon recognized, with a few historic exceptions. The AOU

37 Check-list quickly became the nomenclatural standard for the U.S. and Canada (Dwight 1909) and has

38 remained so for nearly 135 years. Geographic coverage was expanded to include all of continental

39 North America (adding Middle America-Mexico through Panama), Hawaii, and the West Indies

40 with the $6^{\text {th }}$ edition (AOU 1983). It is now the recognized standard for the areas it covers.

The Check-list is the work followed by most field guides in this region, and thus by

43 birdwatchers and bird hunters, and it provides the formal scientific basis for avian diversity and its

44 management and conservation in the U.S., Mexico, and (in part) Canada (Canadian Migratory Birds

45 Convention Act 1994, USFWS 2000, Berlanga et al. 2019). Given the importance of a scientific basis

46 for avian management and conservation and the legal frameworks for these undertakings, this

47 strength of the Check-list has been recognized for the better part of a century (Lloyd 1922). The

48 Check-list has also been the taxonomic basis for the North American Breeding Bird Survey, the Bird

49 Banding Laboratory, eBird, many other institutional and community science endeavors, and for our

50 society journals (Auk, Condor, etc.). The Check-list is also followed by the major global avian

51 checklists and therefore has global impact among a myriad of constituencies. Science has been a core

52 constituency since the beginning.

The Check-list has been produced and updated since its inception by a committee of

55 volunteer ornithologists with substantial expertise in systematics and taxonomy. It is currently called

56 the North American Classification Committee (hereafter Committee) of the AOS. Scientific names

57 are determined under a taxonomic code with rigid rules, now based on international conventions

58 that apply to all of zoology (AOU 1886, ICZN 1999). Vernacular (English) names are not amenable

59 to similar treatment and so do not have their own detailed Code. The first edition of the Check-list

60 provided a separate outline of how the vernacular names were chosen (AOU 1886; Appendix I

61 below). These procedures remained largely unchanged until the $6^{\text {th }}$ edition (1983; Appendix II). At 
62 that time, many new species formerly lacking English names were added as geographic coverage was

63 expanded to include all of North America. The $7^{\text {th }}$ edition of the Check-list (AOU 1998:xiii) added

64 some minor changes, such as using Eurasian names for species found in the Americas due to

65 vagrancy. In 2019 the Committee again updated its English names guidelines (AOS NACC 2020).

There has been controversy since the beginning about many aspects of the English names

68 provided by the Check-list, and a century of exchanges has played out in the Auk, Condor, and Wilson

69 Bulletin (e.g., Seton 1885, Grinnell 1906, Potter 1984). Considerations of the Committee's approach

70 can be found in Dwight (1909) and Griscom (1947). Dwight (1909), a member of the Committee,

71 addressed recurring movements to reform vernacular names and urged conservatism, stating that

72 'There is hardly a name on the list that would not be subject to removal if everybody's whims were

73 consulted." (p. 45). He further wrote that "Our Check-List must be popular if it is to retain its

74 authoritative position as to vernacular names and the utmost conservatism is necessary if it is to

75 keep in touch with the rank and file of the army of people who take a deep interest in North

76 American birds.” (p. 45). Because nomenclatural stability improves communication, it has been

77 reaffirmed as an important principle of the committee since that time (Dwight 1909, Griscom 1947,

78 AOU 1983, AOS NACC 2020). Therefore, the Committee's longstanding approach has been that

79 changes of any kind, including changes to English names, must present a compelling and well-

80 researched rationale.

81

Griscom (1947), knowledgeable but not a member of Committee, provided an outsider's

83 perspective in addressing arguments to reform English names in the Check-list. His eloquent

84 summary remains valuable for those concerned about such changes today. Based on criticisms of the

85 time (which included calls to improve poor descriptive names), he estimated that $80 \%$ of English

86 names then in the Check-list would have to be changed to meet those critiques. He also recognized

87 that whatever names are chosen for species in the Check-list "they will be soundly denounced by a

88 certain percentage" (p. 136). He considered that proposers of reforms should be prepared to

89 surmount four hurdles that remain pertinent today: (1) whether reforms would be complete or

90 partial and, if partial, where to draw the lines; (2) the amount of work and time this would take; (3) 
91 the need for a synonymy to keep track of changes so they would not become "a burden and a

92 handicap to scientific work" (p. 136); and (4) some means of ensuring stability across time and

93 committees. He considered that:

94

95

96

97

98

99

100

101

102

103

104

105

106

107

108

109

110

111

112

113

114

115

116

117

118

119

$$
\begin{aligned}
& \text { "The protagonists of reform in vernacular names must pass from } \\
& \text { destructive to constructive criticism. Their criticisms are perfectly } \\
& \text { valid; they have merely discovered for themselves what ornithologists } \\
& \text { have known for a century: vernacular names in every language, and } \\
& \text { scientific and technical names as well, are replete with absurdities, } \\
& \text { inaccuracies, and false taxonomic implications..." (p. 137). }
\end{aligned}
$$

To this list we would add today an inherently Eurocentric historic legacy and potentially offensive or exclusionary components.

The long history of the Check-list as the standard reference for English bird names has been overlooked recently in some dialogues. For example, Wright (2018) related his view that the AOU began this task only in preparation for the $5^{\text {th }}$ edition of 1957 . It seems that readers have become confused by the 1886 Code for zoological nomenclature (= scientific names) and overlooked the separate treatment of vernacular (English) names later in the same volume (AOU 1886; these criteria are given in Appendix I below). This misapprehension is not new, however. For example, Choate (1973) also thought the AOU began English name standardization with the $5^{\text {th }}$ edition. Both are incorrect, as the Committee has performed this task since 1886 (Dwight 1909), albeit with a few historic species-level gaps. During part of the $20^{\text {th }}$ century, their overly close focus on subspecies caused some full species to lack or have inconsistent names. For example, Song Sparrows (Melospiza melodia) and Fox Sparrows (Passerella iliaca) were fine, but towhees (Pipilo spp.) were a mess. Those remaining issues were fully resolved with the $5^{\text {th }}$ edition of 1957.

Standardizing English names for birds was a necessary and foundational part of the Checklist, as originally recognized (AOU 1886, Grinnell 1900), but this goal has had detractors since that 
time. Ernest Thompson Seton (1885), a noted naturalist and regular contributor to The Auk, decried

121 the forthcoming Check-list's (AOU 1886) attempt to standardize English vernacular names. He was

122 opposed to many of the names themselves but also to standardization, feeling strongly that popular

123 names, locally known and understood, fostered better communication about birds. In failing to

124 recognize that you can do both — standardize names and use other, better known local names to

125 foster local communication-he overlooked the fact that we already do this by giving birds English

126 names in addition to their scientific names. As his promotion of using Skylark in place of Sprague's

127 Lark [now Pipit] showed (Seton 1885), this approach can work well locally while still inhibiting

128 broader communication: Sprague's Pipit, Anthus spragueii, is not only a different species but is in a

129 different family than the Eurasian Skylark, Alauda arvensis.

Years later, Seton (1919) again emphasized that popular interest in birds suffers from

132 choosing poor names. He gave many examples of names he disagreed with, including Black-billed

133 Cuckoo, Goldfinch, Cardinal, Barred Owl, American Kestrel, Prothonotary Warbler, Blackburnian

134 Warbler, Clay-colored Sparrow, and Western Grebe. He gave his central argument thus:

"If the ornithologists had set out definitely to build an eternal barrier to popular interest in birds, they could not have done it better than by establishing such impossible names as are cited above. They never were, and never could be, English names.” (Seton 1919:233).

With tens of millions of birdwatchers today in the U.S. alone, this challenge proved not to be

142 a very effective barrier. Instead of standardized names, Seton (1919) felt that English names should 143 effectively undergo a popularity contest (without regard to names of birds in parts of the Americas 144 where English is not the primary language), and only then "make it nation-wide." He was not alone 145 in suggesting that popularity be a driving criterion (e.g., Lewis 1920, Griscom 1947). Yet some

146 winnowing had to be done; common birds especially had and have a lot of vernacular names (e.g., 147 Trumbull 1888). Burns (1916), for example, diligently found and compiled a list of 132 names for 148 Colaptes auratus, the species known today as the Northern Flicker. 
McAtee (1923), an assiduous collector and compiler of vernacular names, was also opposed

to standardization. Yet his own monumental, multi-decadal work amassing vernacular names testifies to the vast number of alternatives. Kalmbach (1968) summarized McAtee's massive work on names for birds in North America north of Mexico. By the mid-20th century, when the project was ultimately abandoned, McAtee had already assembled about half a million names used for the birds of this region (most but not all are in English), and he had a typed manuscript for Vol. 1 of 1,697 pages. The approximately 67,000 citations underlying this work and its index had not yet been typed. Olson (2001) reviewed a published German work of similarly impressive magnitude. The implication is that birds have many vernacular labels where they occur, and standardization is necessary to arrive at one name to enable widely effective communication. We cannot expect such a process to result in unanimous agreement, as Seton $(1885,1919)$ and numerous other authors of the $20^{\text {th }}$ century have shown and as continuing interest in name changes shows.

The Committee in charge of the Check-list has always been open to suggestions and proposals on English names and is still so today. It frequently seeks input from others, e.g., with a subcommittee on spelling (Cheesman \& Oehser 1937), regular consultation with the American Birding Association (e.g., AOU 1983: xxi) for past editions of the Check-lists and Supplements (see acknowledgments there), and consultation with the AOS Committee on Diversity and Inclusion on recent proposals with social justice implications. Complete agreement regarding proposals and suggestions is frequently not achieved, even among committee members (Eisenmann 1955, recent votes posted on the AOS NACC web site). One large change in English names by the Check-list was in adopting many of the spelling changes recommended by Cheesman \& Oehser (1937). Another was in ceasing to use English names for subspecies, which occurred between the $4^{\text {th }}(1931)$ and $5^{\text {th }}$ (1957) editions.

Arguments opposed to and in favor of eponymous names-people, things, or places named after people-have long been part of this history. One hundred years ago, Lewis (1920) proposed that all eponymous English bird names be replaced (among other suggested changes). This topic has 
178 recently been reinvigorated by renewed appreciation for how bird names intersect with matters of 179 social justice, most prominently via a recent letter to AOS

180 (https://birdnamesforbirds.wordpress.com/, Petition) that advocates for change using a remarkably 181 broad brush: "eponymous honors and other potentially derogatory, oppressive, or simply irrelevant 182 holdovers in English common names.” As presented in the current English name guidelines (AOS 183 NACC 2020), there is widespread recognition that matters of inclusion are relevant to considerations 184 about the English names of birds, so this fundamental principle is not a source of disagreement. The 185 central challenge, as it has been for over a century, is where to draw the line between the advantages of stability and the desire to identify and remove potentially exclusionary or harmful associations.

The perennial challenge is that there is no clean dividing line where names on one side are unacceptably offensive and names on the other side are not. One reason for this is that these valid 191 example, consider the name of the American Robin, a familiar and widespread bird species.

192 "American" is problematic for being a geographic region eponymously named after Amerigo

193 Vespucci, an archetypical Florentine explorer/colonizer, and for being often conflated with the 194 "United States of America" to the exclusion of other places where this species occurs. "Robin" is 195 similarly problematic for being an Anglocentric application of the pre-existing English word for a 196 very different bird in another family (Erithacus rubecula). Thus, American Robin has a set of 197 eponymous, colonialist, nativist, and 'irrelevant holdover' characteristics. In considering possible 198 alternatives we could go back to Catesby and resurrect Fieldfare, which would at least put the 199 English name into the right family, but Fieldfare (Turdus pilaris) is already taken, so we would have to 200 come up with an acceptable modifier (probably not Carolina Fieldfare, as could be obtained from 201 Catesby, inasmuch as Carolina is eponymously named after King Charles I; Trotter 1909). Although 202 the details vary, similarly valid historical (and potentially negative) connections apply to hundreds of 203 other North American bird names that are not direct eponyms. And ultimately, no matter how much 204 work we could put into credibly changing all bird names that fit under the broad umbrella quoted 205 above, we'd still be left with the colonialism (i.e., oppressive and potentially derogatory aspects) 206 inherent in having English and scientific names at all. 
Eponymous names have been common in Western cultures since at least the ancient Greeks

209 (from whose language the term is derived). Such names for birds have been with us since avian 210 nomenclature began. In North America, the birds of California are particularly rich in this type of

211 English name (Palmer 1928), whereas Middle American birds have comparatively few (Eisenmann

212 1955, AOU 1983). Many present-day calls to remove eponyms in English bird names stem from a

213 meritorious desire to make ornithology and birding more inclusive. Similar arguments about names

214 and other historical symbols are relevant to many aspects of our culture today. For example, North

215 American ornithological societies have celebrated the contributions of our predecessors and

216 members in other ways (Palmer 1917, 1928), including the many eponymous awards of our

217 professional societies. This has been a prominent tradition in ornithology, other branches of zoology

218 and botany, and, indeed, in society more broadly (e.g., awards, prizes, buildings, roads, bridges,

219 mountains, rivers, lakes, cities, towns, positions, medicine, and companies). Changes to some of

220 these historically based labels may happen as a component of broad-based societal change.

221 However, given the nature of the Check-list as an intentionally stable authority, it would be a

222 deviation from its longstanding practices for the Committee to eliminate eponymous names before

223 observing a widespread trend towards similar changes among Check-list stakeholder groups, other

224 bird nomenclature authorities (not to mention those for other organismal groups), and in broader

225 society. This seems likely to remain a source of tension given that some such stakeholders favor

226 rapid and widespread change in how the Check-list handles eponyms based on principles of 227 inclusivity.

Because English bird names are proper nouns or proper names, once they've been in circulation for a long time that name is the bird to most people, and, for eponymous names, relatively few people today know or give much thought to whom the name honors. For a parallel example, when we think of New York, the name is the city; few will know or think of the place it was named after, York, a name that derives from Vikings, and Romans, and battles, and associated 235 (Cardellina pusilla), not Alexander Wilson, widely considered the founder of North American 
ornithology. And, unlike the scientific name, this English name has been unchanged since 1886. Not every person after which a bird has been named should continue to be, but at the same time stability

238 and clarity of communication are achieved when we use well established nouns like "New York" and "Wilson's Warbler."

There have been recent suggestions that Native American names should be available for

242 every bird and that these might be given preference over English names, a suggestion that has some

243 inherent merit. Challenges to adopting this approach in areas outside of Hawaii (with its endemic

244 avifauna and one major Native culture and language in which nearly all living birds have one well-

245 documented name) include: (1) Native names are often not available for all of the birds that the

246 original Americans would know and have named (Cooke 1885). (2) Most continental bird species are

247 sufficiently widespread that they would have names in many different Native American languages,

248 requiring a new process (and an inherent lack of full agreement) to choose one such name over

249 others. (3) While English is rich in words borrowed from other languages (e.g., vireo, junco), an

250 English names list should probably be predominantly just that, for most effective communication in

251 English. Importantly, this does not preclude adoption of new names from other languages, and it

252 does not preclude developing corresponding lists in English and other languages. (4) In coopting

253 Native names into an inherently non-Native nomenclatural system, ornithology risks cultural

254 appropriation and creating other kinds of harm (e.g., Scafidi 2005).

256 Conclusions

257 English bird names increase effective communication and make ornithology more accessible.

258 Every edition of the Check-list of North American Birds and its Supplements has included English and

259 scientific names. Standardizing the English name has been important, and a choice usually needs to

260 be made, especially among widespread birds with many names. The Check-list has been the standard

261 for North America for over a century, and it underpins the legal basis for avian management and

262 conservation across most of the continent. Choices for English names in the Check-list have been

263 made under clear criteria (Appendices I-III) that are responsive to increased knowledge and

264 changing societal mores (AOS NACC 2020). For many different reasons, since the first Check-list, 
many people have been unhappy with choices made about particular English bird names and about the underlying processes. It is clear that there is no approach that will achieve universal consensus, yet there are considerable merits to a standardized and widely adopted approach to English bird names.

\section{Acknowledgments}

Many thanks to my fellow committee members: Shawn Billerman, Kevin J. Burns, Terry Chesser, Carla Cicero, Jon L. Dunn, Andrew W. Kratter, Irby J. Lovette, Nicholas A. Mason, Pamela C. Rasmussen, J. V. Remsen, Jr., and Douglas F. Stotz; to former committee members, Richard Banks and the late Kenneth C. Parkes and Jim Rising; and to Daniel Gibson and Jack Withrow. I have enjoyed our many discussions on these issues. Thanks also to Irby Lovette, Terry Chesser, Pamela Rasmussen, Carla Cicero, and Rick Wright for comments on an earlier draft. Opinions and any remaining errors are my own.

\section{Literature Cited}

American Ornithological Society (AOS), NACC. 2020. Guidelines for English Bird Names. https:/ / americanornithology.org/nacc/guidelines-for-english-bird-names/ American Ornithologists' Union (AOU). 1886. The Code of Nomenclature and Check-list of North American Birds. New York, American Ornithologists' Union.

American Ornithologists' Union (AOU). 1983. Check-list of North American Birds, Sixth edition. American Ornithologists' Union, Lawrence, Kansas.

Berlanga, H., H. Gómez de Silva, V. M. Vargas-Canales, V. Rodríguez-Contreras, L. A. SánchezGonzález, R. Ortega-Álvarez y R. Calderón-Parra (2019). Aves de México: Lista actualizada de especies y nombres comunes. CONABIO, México D.F. Retrieved 8 May 2021 from https://www.biodiversidad.gob.mx/media/1/cienciaciudadana/documentos/Lista actualizada aos 2019.pdf

Burns, F. L. 1916. One hundred and thirty-two vernacular names for the flicker. Wilson Bulletin 28:90-91.

Canadian Migratory Birds Convention Act (1994.) Birds Protected in Canada. Retrieved 8 May 2021 from

https://www.canada.ca/en/environment-climate-change/services/migratory-birds-legalprotection/list.html

305

Choate, E. A. 1973. The Dictionary of North American Bird Names. Gambit, Boston. 
Cooke, W. W. 1885. Indian bird names. Auk 222-223.

Dwight, J., Jr. 1909. The popular names of birds. Condor 11:43-45.

Eisenmann, E. 1955. The species of Middle American birds. Transactions of the Linnaean Society of

Grinnell, J. 1900. Against the general use of scientific names. Condor 2:20-21.

Grinnell, J. 1906. Better vernacular names. Condor 8:154-155.

Griscom, L. 1947. Common sense in common names. Wilson Bulletin 59:131-138.

International Commission on Zoological Nomenclature (ICZN). 1999. International Code of Zoological Nomenclature, Fourth edition. ICZN, London. (available online here: https://www.iczn.org/thecode/the-international-code-of-zoological-nomenclature/the-code-online/ )

Kalmbach, E. R. 1968. American bird names their histories and meanings. Auk 85:703-706.

Lewis, H. F. 1920. Popular bird names. Auk 37:634.

Lloyd, H. 1922. Popular names. Auk 39:144.

McAtee, W. L. 1923. Thoughts on English names for birds in the A. O. U. Check-list. Condor 25:23-25.

Palmer, T. S. 1917. Personalia in ornithology - report of the Committee on Biography and Bibliography. Auk 36:445-452.

Palmer, T. S. 1928. Notes on persons whose names appear in the nomenclature of California birds. Condor 30:261-307.

Potter, E. F. 1984. On capitalization of vernacular names of species. Auk 101:895.

Rowan, W. 1920. Popular nomenclature. Auk 37:499-505.

Scafidi, S. 2005. Who Owns Culture?: Appropriation and Authenticity in American Law. Rutgers University Press.

Seton, E. S. 1885. The popular names of birds. Auk 2:316-317.

Seton, E. S. 1919. On the popular names of birds. Auk 36:229-235.

Stone, W. 1934. Correspondence. Auk 51:281. 
351 Trotter, S. 1909. An inquiry into the history of the current English names of North American 352 landbirds. Auk 26:346-363.

354 Trumbull, G. 1888. Names and portraits of birds which interest gunners, with descriptions in 355 languages understanded of the people. New York, Harper \& Brothers.

USFWS (2000.) 50 CFR 10.13 - List of Migratory Birds. Retrieved 8 May 2021 from

358 https://www.govinfo.gov/app/details/CFR-2000-title50-vol1/CFR-2000-title50-vol1-sec10-13

360 Willughby, F., and J. Ray. 1678. The Ornithology of Francis Willughby of Middleton in the County 361 of Warwick. London: John Martyn.

362 


\title{
I. AOU (1886:68-69)
}

\author{
\16. Of the Selection of Vernacular Names.
}

RECOMMENDATION X. Vernacular names, though having no standing in scientific nomenclature, and being not strictly subject to the law of priority, have still an importance that demands the due exercise of care in their selection, especially with reference to their fitness and desirability.

REMARKS - It not infrequently happens that well-known, abundant, and familiar species have several nearly equally familiar vernacular designations, in which case the most euphonious and otherwise most fitting should be selected and given prominence. In the case of two equally unobjectionable names, the earliest should be given preference. In general, vernacular names may well be selected on the auctorum plurimorum [of most authors] principle. Since many species known to science are without vernacular names, otherwise than unknown barbarous ones, and since it is necessary, or at least desirable, sooner or later to supply them with vernacular designations, these should be as far as possible formed by translating, or in part adopting, the technical names of science; and authors of monographic works, like, for example, the British Museum 'Catalogue of Birds,' or faunal works, like many which might be named, (but which unfortunately in too many cases ignore vernacular names,) would do their fellow naturalists, and through them the public, a favor by considerately supplying vernacular designations to species, particularly in such departments of Zoology as Mammalogy and Ornithology, and indeed Vertebrates generally, together with the better known or more exemplary forms among Invertebrates.

\section{AOU (1983: xxi-xxiii)}

English names. The Committee follows the policy guidelines of Eisenmann (1955, Trans. Linn. Soc. N.Y., 7, pp. 1-1 28) and Eisenmann in Meyer de Schauensee's "The Species of Birds of South America and Their Distribution" (1966) in regard to choice of names. With respect to orthography and related matters, we follow Cheesman and Oehser (1937, Auk, 54, pp. 333-340) and Parkes (1978, Auk, 95, pp. 324-326). Opinions were sought and received from the Check-list Committee of the American Birding Association and others with a major interest in English names, and we appreciate their cooperation and detailed analysis of English name problems. There is much concern about changes in both scientific and English names of birds. However, absolute stability is not possible in either set of names. Progress in systematic ornithology often dictates changes in scientific names in accordance with nomenclatural codes, and a broadening world-wide experience with birds has indicated that some changes in English names help to avoid confusion and promote uniformity.

In general, the policy guidelines are as follows:

1. Retain well established names for well known and widely distributed species, even if the group name or a modifier is not precisely accurate, universally appropriate, or descriptively the best possible. For example, the group names flycatcher, warbler and oriole are applied to New World 
species that are not confamilial with Old World taxa to which these same English group names are applied, but in both areas the names are so well established and the differences in relationship so well known that there is little confusion. Species such as the Common Tern are not everywhere "common," the Tennessee Warbler occurs in many other areas, and the Purple Finch is more red than purple. Changing such long established names would only contribute to confusion, not lessen it.

2. For species or groups with extensive extralimital distributions, use English names that are generally accepted on a world-wide basis, provided that such a name does not duplicate another well-established one and is not otherwise inappropriate. For example, we have adopted "Common Moorhen" for Gallinula chloropus and "moorhen" as the group name for all species of Gallinula, and likewise have adopted "harrier" as the group name for hawks of the genus Circus. These group names have long been established for these widely distributed forms in the rest of the Englishspeaking world. In a few cases of widely distributed species having long established, perhaps equally appropriate names in North America and in Eurasia (such as "Oldsquaw" and "Long-tailed Duck," respectively, for (langula byemalis), we have retained the American name.

3. Use modifiers for all single-word or group names that are applied to more than one species. For example, Gray Catbird, not simply Catbird, is used for Dumetella carolinensis, as the closely-related Melanoptila glabrirostris is called the Black Catbird. Troglodytes troglodytes is usually known as "The Wren" in English-speaking regions of the Old World where it is the only species of wren present; this unmodified name is inappropriate for the Check-list area, where there are other congeneric and confamilial species known as wrens. In general, modifiers that are comparative terms should have parallel construction, as in Greater Yellowlegs (Tringa melanoleuca) and Lesser Yellowlegs (T. flavipes); however, we have not rigidly adhered to this policy in cases of well established names such as Great Black-backed Gull (Larus marinus) and Lesser Black-backed Gull (L. fuscus).

4. In the New World tropics there are many species for which there are no well established English names. Some earlier authors of reference works on Neotropical birds knew some species only from a few study skins and coined names that often proved seriously inappropriate in the light of later knowledge. Previously published names should be used, however, if they are reasonably appropriate and/or well established. We have followed Eisenmann (loc. cit.) and Eisenmann in Meyer de Schauensee (loc. cit.) in conserving such names and in adopting newer ones to replace those that were not well established and were also descriptively inaccurate or suggested wrong relationships or distributions, or were obscure and uninformative patronyms. A new name should be informative about some distinctive aspect of the bird's appearance, habits, relationships or distribution, or some combination of these that is not too lengthy. For example, we have adopted Chihuahuan Raven for Corvus cryptoleucus, a name suggested to us by several persons; normally, we would not replace a well known name such as White-necked Raven, no matter how inappropriate, but our policy would require the additional modifier "American" (because of an African species by the same name), producing a name cumbersome as well as inappropriate.

5. When two taxa previously recognized as different species with different English names are merged, a name applicable to both is needed. If neither taxon has an English name that is suitable for both, a new name must be provided. The few such names proposed by the Committee are intended to be informative rather than fanciful. For example, the taxa listed in the fifth edition as the Myrtle Warbler (Dendroica coronata) and Audubon's Warbler (D. auduboni) are considered conspecific in this Check-list under the scientific name D. coronata, which has priority. The preferred English 
name is Yellow-rumped Warbler, which has been used in recent years in most publications; this name is equally descriptive of all populations of both forms. Where we have merged two or more forms or divided one form into two or more, we have in the "Notes" section suggested appropriate English names for the taxa if treated in the other mode.

6. Vernacular names derived from a language other than English may be adopted when these are well established and not inappropriate. Many well known names are, of course, derived from classical or other European languages and some are based on verbal names from unwritten native languages. The endemic Hawaiian avifauna includes many species for which Hawaiian-language names are well established and used in English-language publications. We have generally followed authorities on Hawaiian birds in the use of these names, but for species belonging to widespread groups, we have chosen English names that we felt were more informative (e.g., Hawaiian Goose instead of Nene, Hawaiian Crow instead of Alala).

We are fully aware that it is impossible to achieve universal agreement on the best choices for English names, and some differences in preference are inevitable. The Committee hopes that its choices will be acceptable to those who use primarily English names; those requiring greater uniformity may use Linnaean nomenclature.

III. AOS 2020. https://americanornithology.org/nacc/guidelines-for-english-bird-names/

\section{Guidelines for English Bird Names}

The American Ornithological Society's North American Classification Committee (NACC) has long held responsibility for arbitrating the official names of birds that occur within its area of geographic coverage. Scientific names used are in accordance with the International Code of Zoological Nomenclature (ICZN 1999); the committee has no discretion to modify scientific names that adhere to ICZN rules. English names for species are developed and maintained in keeping with the following guidelines, which are used when forming English names for new or recently split species and when considering proposals to change established names for previously known species.

\section{A. Principles and Procedures}

1. Stability of English names. The NACC recognizes that there are substantial benefits to nomenclatural stability and that long-established English names should only be changed after careful deliberation and for good cause. As detailed in AOU (1983), NACC policy is to "retain well established names for well-known and widely distributed species, even if the group name or a modifier is not precisely accurate, universally appropriate, or descriptively the best possible." The NACC has long interpreted this policy as a caution against the ever-present temptation to 'improve' well-established English names and this remains an important principle. In practice, this means that proposals to the NACC advocating a change to a long-established English name must present a strongly compelling, well-researched, and balanced rationale.

2. Name change procedures. The NACC process of considering an English name change is the same as for other nomenclatural topics. NACC deliberations are proposal-based, and the committee welcomes proposals from interested members of the professional and non-professional 
ornithological communities. Proposals from previous years, which may be useful as models, are posted online, as are general instructions for proposal preparation and submission. Proposals to change an established English name require a $2 / 3$ vote in favor for passage, following the committee's long-standing policy for all proposals.

\section{B. General Guidelines for English Bird Names}

1. Orthography. English names of birds are capitalized in keeping with standard ornithological practice. As noted by Parkes (1978), capitalization also prevents ambiguity between a species name and a description in such cases as "gray flycatcher" or "solitary sandpiper". Diacritical marks are not used in English names. With respect to the use of hyphens, the committee follows Parkes (1978).

2. Uniqueness. The English name of every species (and of named groups within species) should be unique both within the NACC region and, with occasional exceptions, globally.

3. Length of names. Names may consist of a single word or more than one word. However, modifiers must be used for single word or group names that apply to more than one species. Thus, Gray Catbird is used for Dumetella carolinensis rather than Catbird because there are other species of catbird (e.g., the closely related Black Catbird Melanoptila glabrirostris and eleven distantly related species of catbirds in the family Ptilonorhynchidae).

4. Eponyms. Eponyms, names that incorporate the name of an individual historical person, add an apostrophe "s" ending (e.g., Baird's Sparrow, Lucy's Warbler). Eponyms already ending in "s" also add an apostrophe "s" (e.g., Xantus's Hummingbird).

5. Geographical names. Names based on geography may use either the adjectival (e.g., Jamaican Woodpecker) or noun (e.g., Canada Warbler) form of a name, but names should be used consistently for each geographical entity.

6. Species marginally distributed in North America. Names generally accepted by global or regional authorities are typically used for species that occur in our area as vagrants, introduced species, or species of otherwise marginal distribution.

\section{New and Modified Names Based on Changes to Classification}

1. Typical species splits. In the case of true phylogenetic daughter species formerly treated as a single parental species, the usual policy is to create new names for each daughter species. For example, the split of Solitary Vireo resulted in new names for each of the three daughter species (Blue-headed, Cassin's, and Plumbeous) rather than retention of Solitary Vireo for one of the daughters. This practice is designed to prevent confusion in the literature as to what taxonomic entity the parental name (e.g., Solitary Vireo) references. Note that this differs from the procedure used for scientific names, which mandates (via ICZN) that the name of the nominate form remain unchanged. In support of the principle of stability, the choice of new names strongly considers existing names for the daughter species in widely used older literature (e.g., Ridgway and Friedmann 1901-1946) as well 
as any names proposed for the new species in publications supporting the change in species limits.

1.1 Exceptions. Strong association of names with particular daughter species may provide exceptions to the above policy. In these situations, a change to the English name of one daughter species would cause much more disruption than a change to that of the other daughter species. In these cases, the potential confusion of retaining the parental name for the daughter species strongly associated with the name is weighed against the potential disruption of changing the name. Overall, the goal is to maximize stability and minimize disruption to the extent possible. The committee uses various factors to assess potential differential impact, such as major differences in range size, differences in usage in the scientific and popular literature, and relative appropriateness of a name. The Committee recognizes that such judgments are subjective and that borderline cases will inevitably occur.

1.1.a. Relative range size. In many cases, relative range size is an excellent proxy for the differential effect of a name change. When one or more new daughter species are essentially peripheral isolates or have similarly small ranges compared to the other daughter species, then the parental name is often retained for the widespread, familiar daughter species to maintain stability. For example, the English name Red-winged Blackbird was retained for the widespread species Agelaius phoeniceus when the Cuban subspecies $A$. phoeniceus assimilis was elevated to species rank, and a novel English name (Red-shouldered Blackbird) was adopted only for the daughter species $A$. assimilis.

1.1.b. Differential usage. In some cases, a name is much more associated with one daughter species regardless of relative range size. For example, the name Clapper Rail has been consistently associated with birds of the eastern US and Caribbean for over a century, whereas populations in South America and in the western US and Mexico were known by various other names before being grouped under the name Clapper Rail. In this case, despite the extensive range of the South American daughter species (Rallus longirostris), the name Clapper Rail was retained for eastern North American daughter species (R. crepitans) when the species was split into three, with Mangrove Rail applied to the daughter in South America and Ridgway's Rail to that in the southwestern US and adjacent Mexico (R. obsoletus).

1.1.c. Relative appropriateness. In some cases, a parental name is much more appropriate for one of the daughter species. In such cases, especially when no truly appropriate substitute name can be found, a parental name can be retained for that daughter. For example, in the case of the split of Winter Wren (Troglodytes biemalis), the parental name Winter Wren was retained for the migratory eastern species, whereas the novel name Pacific Wren was created for the largely resident western species (T. pacificus). In this case the retained English name of the eastern species biemalis also reflects its scientific name, which means "of winter" (Jobling 2010).

2. Other species splits. In the case of a change in species limits due to incorrect previous assessment of relationships, then the parental English name may be retained for the appropriate species, especially if no other suitable name is available. This differs from 1 above in that the changes do not involve true parent-daughter splits in the phylogenetic sense but rather a correction of previous taxonomy. For example, when Galapagos Shearwater was split from Audubon's Shearwater, the name Audubon's was not changed because new data revealed that Galapagos was not its sister and 
should never have been considered conspecific with Audubon's in the first place; therefore, the original classification, with both species treated as separate species with their original separate names, was restored.

3. Species lumps. The committee occasionally merges two or more species into a single species. Guidelines for English names that result from lumps generally mirror those for species splits, in that a new name is generally preferred unless the exceptions for relative range size or appropriateness (as above in C.1.1 and C.1.2) apply. In practice, many lumps involve species with a great disparity in geographical range, so that in many cases the name for the more widespread former species is retained for the merged species. In a case in which the lump represents a return to species limits recognized prior to a split (i.e., in a reversal of a split), then the original name for the pre-split species is again adopted (in some cases this is the name of one of the former daughter species).

4. Reallocation of taxa at higher taxonomic levels. In the case of reallocation of taxa at the family or genus level due to new phylogenetic data, the Committee may occasionally change the group name of a species to reflect more accurately its phylogenetic relationships. A classic example is the change of the English name of the species formerly known as Upland Plover to Upland Sandpiper (to restrict the group name "plover" to the Charadriidae). Such changes are evaluated on a case-by-case basis, with assessment of the cost of loss of stability versus the benefit of increasing phylogenetic information in the name. Note that many English group names do not have phylogenetic significance even at the family level (e.g. flycatcher, warbler, finch, sparrow, tanager, grosbeak, and bunting) and are best treated as morphotypes. Thus, changes to long-standing names of this type (e.g., Scarlet Tanager) to correspond to changes in family or genus allocation generally require special circumstances. Again, the Committee recognizes that the inevitable subjectivity in these situations will create borderline situations.

\section{Special Considerations}

1. Eponyms. At present, 142 English names of NACC bird species are eponyms. The NACC recognizes that some eponyms refer to individuals or cultures who held beliefs or engaged in actions that would be considered offensive or unethical by present-day standards. These situations create a need for criteria to evaluate whether a long-established eponym is sufficiently harmful by association to warrant its change. After substantial deliberation and consultation, the NACC has adopted the following guidelines:

1.1 The NACC will change well-established eponyms only in unusual circumstances, but these situations may occur. The NACC recognizes that many individuals for whom birds are named were products of their times and cultures, and that this creates a gradient of disconnection between their actions and beliefs and our present-day mores. By itself, affiliation with a now-discredited historical movement or group is likely not sufficient for the NACC to change a long-established eponym. In contrast, the active engagement of the eponymic namesake in reprehensible events could serve as grounds for changing even long-established eponyms, especially if these actions were associated with the individual's ornithological career. The NACC recognizes that opinions will often differ on how best to handle such situations, and the Committee strives to strike a balance that recognizes the 
principle of nomenclatural stability while respecting circumstances in which names should be reconsidered to reflect present-day ethical principles or to avoid ongoing harm.

1.2 In evaluating potential changes to eponyms, the NACC will also consider the degree of historical association between the eponym and the species it describes. Some eponyms are purely honorific in that they refer to an individual with no close association to their namesake species or to ornithology in general. Other eponyms refer to the individual who first discovered or collected that species, or to individuals who contributed substantially to advances in our discipline. These latter names have a tighter historical and ornithological affiliation and therefore a higher level of merit for retention.

2. Foreign-language names. As stated in AOU (1983), "vernacular names derived from a language other than English may be adopted when these are well established and not inappropriate." For example, the endemic Hawaiian avifauna includes many species for which Hawaiian-language names are well established, and most of these have been incorporated into the AOS Checklist. However, in situations in which no historical Hawaiian-language name is known, the NACC will generally give precedence to an established English-derived name over a Hawaiian-language neologism. Similar principles apply to names derived from non-English languages elsewhere within the NACC area.

667 American Ornithologists' Union (AOU). 1983. Check-list of North American Birds, 6th ed.

3. Derogatory or otherwise offensive names. English bird names that clearly denigrate any group or class of people, or which would be generally considered offensive by present-day standards, may be changed for this reason alone. For example, the English name of the duck formerly known as Oldsquaw was changed to Long-tailed Duck in the 42nd Supplement (AOU 2000). The associated text of that supplement reads in part "The Committee declines to consider political correctness alone in changing long-standing English names of birds but is willing in this instance to adopt an alternative name that is in use in much of the world." The present policy document revises this approach to acknowledge that there may be English names that cause sufficient offense to warrant change on that basis alone. The committee will consider the degree and scope of offensiveness under present-day social standards as part of its deliberations. The NACC acknowledges that some words or terms may become secondarily offensive, even when they were not originally intended as derogatory, and sometimes even when there is no direct etymological link between the original name and its now-offensive connotation.

\section{References}

672

673 International Commission on Zoological Nomenclature (ICZN). 1999. International Code of

674 Zoological Nomenclature, 4th edition. International Trust for Zoological Nomenclature, London.

675

676 Jobling, J. A. 2010. Helm dictionary of scientific bird names. Christopher Helm, London. 
678 Parkes, K. C. 1978. A guide to forming and capitalizing compound names of birds in English. Auk 679 95: 324-326.

680

681 Ridgway, R., and H. Friedmann. 1901-1946. The birds of North and Middle America. Bulletin US 682 National Museum 50, parts 1-10. 